\title{
ANTI-DIABETIC ACTIVITIES OF THE METHANOL LEAF EXTRACTS OF HYMENOCARDIA ACIDA (TUL.) IN ALLOXAN-INDUCED DIABETIC RATS
}

\author{
Ezeigbo, Ihechiluru I. ${ }^{1}$ and Asuzu, Isaac. $\mathbf{U}^{2}{ }^{2}$
}

${ }^{1}$ Department of Veterinary Physiology, Biochemistry and Pharmacology, Michael Okpara University of Agriculture, Umudike, Abia State, Nigeria. ${ }^{2}$ Department of Veterinary Physiology and Pharmacology, University of Nigeria, Nsukka, Enugu State, Nigeria.

E-mail: ihechi2109@yahoo.com

\begin{abstract}
The effect of methanolic extract of Hymenocardia acida leaves on diabetes and associated lipidemia were investigated on experimentally-induced diabetic rats. The extract did not demonstrate any acutely toxic effect in rats within the dose range (250 mg/kg - $2000 \mathrm{mg} / \mathrm{kg}$ ) employed in the study; hence it was well tolerated by the rats. In all experiments, the anti-diabetic effects were dose-dependent and comparable to that of glibenclamide ( $2 \mathrm{mg} / \mathrm{kg})$ standard. At a dose of $500 \mathrm{mg} / \mathrm{kg}$, lipid profile markers such as the serum total cholesterol (TC) levels, LDL-C, triglycerides and HDL-C were significantly lower ( $<<0.05$ ) than those of both the treated and untreated controls.
\end{abstract}

Keywords: Hymenocardia acida, Diabetes mellitus, Lipid profile, Glibenclamide, Alloxan monohydrate

Abbreviations: Hymenocardia acida (HA).

\section{Introduction}

Diabetes mellitus (DM) is a multi-factorial disease characterised by hyperglycaemia and lipoprotein abnormalities (Scoppola et al., 2001). The disease affects approximately more than $5 \%$ of the world's population (Kameswararao et al., 2003). Apart from the hyperglycaemia, several factors including dyslipidemia or hyperlipidemia are involved in the micro- and macrovascular complications associated with the disease; a major cause of morbidity and death (Taskinen, 1993). Diabetic disease is increasing rapidly and vast amounts of resources are spent in all countries (Verspohl, 2002). Currently available therapies for diabetes include insulin and various oral anti-diabetic agents such as sulfonylureas, biguanides, alpha-glucosidase inhibitors, troglitazones, etc; used either as monotherapy or in combination to achieve better glycaemic conditions. Each of the above oral agents suffers from various serious adverse effects. Furthermore, the overall search for anti-diabetic agents has not been rewarded with marketable novel agents in the last two decades (Dewanjee et al., 2008); attempts are still made to find such drugs.

Plants however have played a significant role in the introduction of new therapeutic agents. Metformin was discovered from Galega officinalis, a medicinal plant. In Nigeria, traditional medicine occupies a unique position in health care delivery, especially among the rural populace. However, the activities of herbalists are surrounded with a lot of secrecy and lack of scientific procedure, hence the need to standardise the practice of traditional medicine.

Folkloric uses of the leaves of Hymenocardia acida include the treatment of conditions like diarrhoea (Tona et al., 1999), malaria (Vonthron-Sénécheau et al., 2003), dysentery, diabetes mellitus by the Igede people of Benue State (Igoli et al., 2005), Wounds and Skin diseases (Igoli et al., 2003) and is also shown to have anti-tumour and anti-HIV activities (Muanza et al., 1995). The present investigation was therefore intended to examine the potential anti-diabetic activity of the methanolic leaf extracts of $H$. acida using alloxan induced-diabetic rat model.

\section{Materials and Methods Animals}

Out bred Albino Wistar rats of both sexes weighing 185 - $278 \mathrm{~g}$ were purchased from the Laboratory Animal Facility of the Department of Veterinary Physiology and Pharmacology, University of Nigeria, Nsukka and used. They were kept in clean stainless steel wire mesh cages, maintained at normal temperature and natural daylight/night conditions. They were allowed free access to standard commercial pelleted feed and clean drinking water. Ethical conditions as stipulated by Ward and Elsea (1997) 
in the conducts of experiments with life animals were adhered to strictly. The study protocol was approved by the Faculty of Veterinary Medicine's ethical committee.

\section{Plant material}

Fresh leaves of Hymenocardia acida (HA) were collected in the month of March 2009, from Nsukka metropolis, Enugu state, Nigeria. The leaves were identified as Hymenocardia acida belonging to the family Hymenocardiaceae by Mr. A.O. Ozioko, a taxonomist with the International Centre for Ethnomedicine and Drug Development, Nsukka. Voucher specimen (UNVPP/2009/3001/11) was kept in the herbarium of the Department of Veterinary Physiology and Pharmacology for reference. The Fresh leaves were washed clean with water and dried under mild sunlight. The dried plants were pulverized into coarse powder and $500 \mathrm{~g}$ of the powder were extracted in $80 \%$ methanol for $48 \mathrm{hrs}$ with intermittent shaking. Thereafter, filtration was done using filter papers and funnel into an already weighed beaker. The solvent was allowed to evaporate in an electric oven at $40^{\circ} \mathrm{C}$.

\section{Acute toxicity test}

Five groups of six rats each were used. They were treated orally with varying doses $(250 \mathrm{mg} / \mathrm{kg}, 500 \mathrm{mg} / \mathrm{kg}, 1000 \mathrm{mg} / \mathrm{kg}$ and $2000 \mathrm{mg} / \mathrm{kg}$ ) of HA extract dissolved in water. The rats were allowed free access to feed and water ad libitum and were observed over a period of $24 \mathrm{~h}$ for signs of acute toxicity and death. $\mathrm{LD}_{50}$ was determined using the method of Miller and Tainter (1937).

\section{Hypoglycaemic effect in alloxan-diabetic rats}

Hyperglycaemia was induced by the methods of Vinuthan, et al., (2007). A single intraperitoneal administration of 150 $\mathrm{mg} / \mathrm{kg}$ of freshly prepared alloxan monohydrate in distilled water to overnight fasted rats and observed for hyperglycaemia after 13 days. Thirty diabetic rats of both sexes were randomly divided into five groups containing six animals each and treated thus; the positive control received Glibenclamide ( $2 \mathrm{mg} / \mathrm{kg}$, p.o.) dissolved in distilled water, while the negative control received equal volume of distilled water orally. The test groups were given varying doses- $250 \mathrm{mg} / \mathrm{kg}, 500 \mathrm{mg} / \mathrm{kg}$ and $1000 \mathrm{mg} / \mathrm{kg}$ of the methanolic HA extract, orally. Blood samples were collected at 0, 30, 60 and 120 mins post-treatment by a tail tip-snip cut. The plasma glucose concentration of the rats was determined with the aid of an electronic glucose meter (Accu- Chek Advantage) and glucose strips (Accu-Chek Advantage II). The mean anti-diabetic response observed was recorded as mmol/L and used to determine the dose-response effect of $H$. acida. The results obtained were subjected to one-way ANOVA.

\section{Sub-acute anti-diabetes study}

Thirty (30) rats of both sexes were made diabetic using the methods described by Vinuthan et al. (2007) and randomly divided into three (3) groups of ten (10) rats each and employed in the study. Group A received Glibenclamide (2 mg/kg) and served as positive control. Group B received $500 \mathrm{mg} / \mathrm{kg}$ of the methanolic plant extract of H. acida and Group C received equal volume of distilled water (negative control) every day for seventeen (17) days. The blood glucose levels were determined on day $0,5,11$ and 17 being the last day of the experiment. On the last day all animals were bled from the orbital sinus under mild ether anaesthesia to obtain larger quantity of blood, which was clotted in test-tubes and the sera obtained was used for biochemical assay to determine the lipid profile.

\section{Biochemical estimations}

Serum Total Cholesterol (TC) was evaluated using commercial assay kits following the methods described by Allain et al., (1974). The experiment was done in triplicates. Mean values were obtained and used for the following calculation:

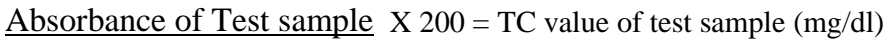

Absorbance of standard

Low Density Lipoproteins (LDL-C) was determined as the difference between total cholesterol and cholesterol content of the supernatant after precipitation of the LDL fraction by Polyvinyl sulphate (PVS) in the presence of Polyethylene-glycol monomethyl ether (Bergmenyer, 1985). The experiment was done in triplicate for each sample and the mean was used for the following calculation:

LDL-Cholesterol $(\mathrm{mg} / \mathrm{dl})=\mathrm{TC}(\mathrm{mg} / \mathrm{dl})-1.5 \mathrm{X}$ Supernatant cholesterol $(\mathrm{mg} / \mathrm{dl})$.

Serum Triglycerides (STG) was estimated by adopting the method of Footsati and Principe (1982). Absorbances of all the tubes were taken spectrophotometrically at $520 \mathrm{~nm}$ wavelength. The results were obtained in triplicates. The mean of which was used for the following calculation:

$$
\frac{\text { Abs of Unknown }}{\text { Abs of standard }} \text { X Concentration of standard (mg/dl) = STG Value of unknown (mg/dl) }
$$


High Density Lipoproteins (HDL-C) in serum were also calculated as per Friedewald's equation (Friedewald et al., 1972). The Friedewald's equation estimates the value of HDL-C using the values of other cholesterol such as LDL-C. HDL-C $=$ TC - LDL-C $-k$ STG

Where HDL-C is High density lipoprotein

LDL-C is Low density lipoproteins

STG is Serum triglycerides

Constant value, $k$ was 0.20 , measurements were taken in $\mathrm{mg} / \mathrm{dl}$.

\section{Data analysis}

Data obtained were presented as mean \pm SEM and analysed using one-way analysis of variance (ANOVA) and post-hoc comparisons were carried out using Dunnet's $t$-test. Values of $P<0.05$ were considered significant in the study.

\section{Results \\ Plant Extraction}

The $80 \%$ methanol extract of HA leaves was dark brown in colour. The yield of the extract was $27.49 \mathrm{~g}(5.5 \% \mathrm{w} / \mathrm{w})$.

\section{Acute toxicity}

No deaths were recorded after $24 \mathrm{hrs}$ of administration of the various doses $(250 \mathrm{mg} / \mathrm{kg}, 500 \mathrm{mg} / \mathrm{kg}, 1000 \mathrm{mg} / \mathrm{kg}$ and $2000 \mathrm{mg} / \mathrm{kg}$ ) of the methanolic extract of $H$. acida. All the rats treated with the extract were dull; clustered together for about seven hours following the oral administration of the extract. The rats recovered 9 hours post administration and became very active.

\section{Hypoglycaemic effect}

All doses (250, 500 and $1000 \mathrm{mg} / \mathrm{kg}$ ) of the extract and glibenclamide $(2 \mathrm{mg} / \mathrm{kg}$ ) when compared to the untreated control, significantly reduced the fasting blood glucose levels of alloxan diabetic rats. There was a significant rise in the mean fasting blood glucose level of the rats treated with $250 \mathrm{mg} / \mathrm{kg}$ of the test extract, $6 \mathrm{hrs}$ post treatment compared with untreated control (Figure 1). The $500 \mathrm{mg} / \mathrm{kg}$ dose showed a time-dependent anti-diabetic activity throughout the duration of the experiment, hence it was the preferred dose for the sub-acute anti-diabetes study.

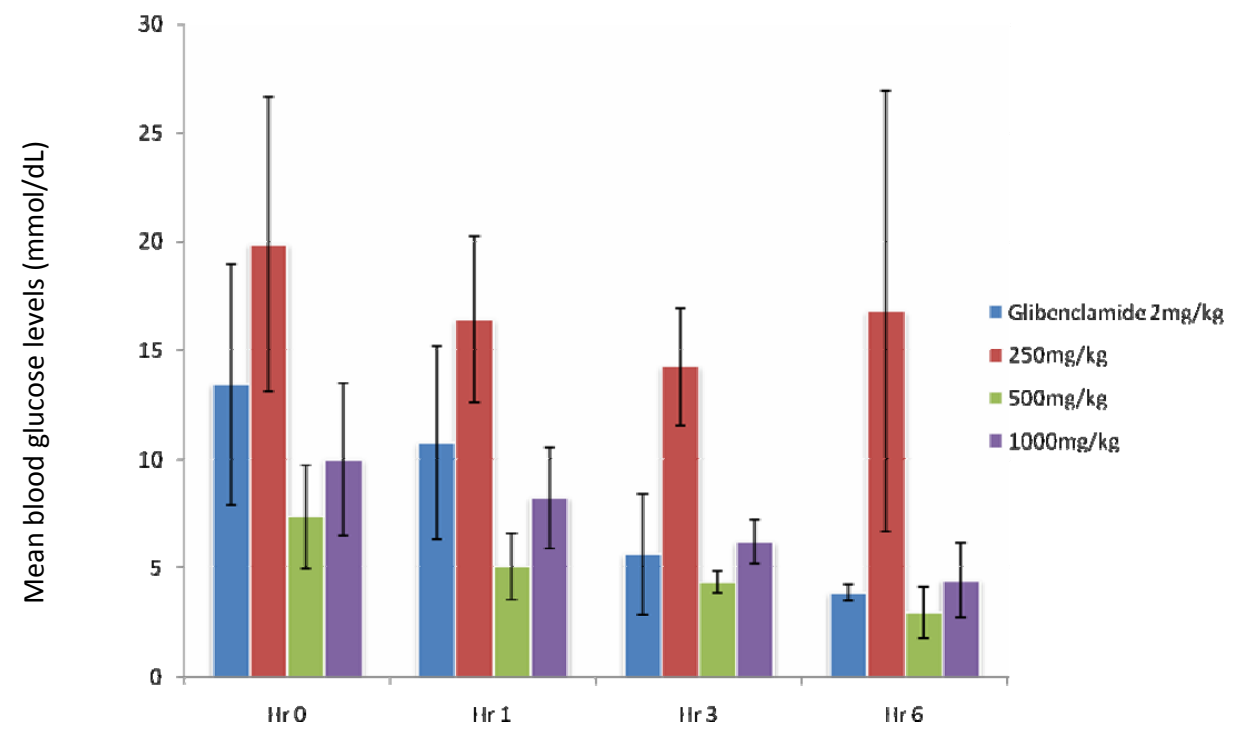

Figure 1: Time-response effect of various doses of the methanolic leaf extract of $H$. acida 


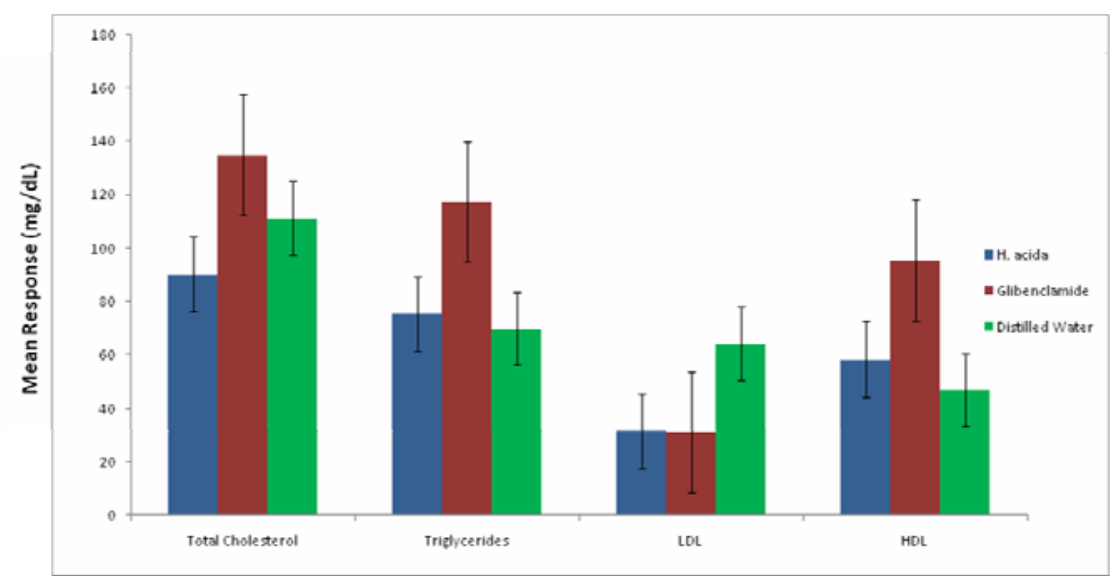

Figure 2: The effect of the oral administration of the methanol extract of $H$. acida on serum total cholesterol, triglycerides, low density lipoproteins and high density lipoproteins

\section{Biochemical assay}

Figure 2 shows the effect of the oral administration of the methanol extract of $H$. acida on serum total cholesterol, triglycerides, low density lipoproteins and high density lipoproteins. The rats treated with glibenclamide showed a marked increase in total cholesterol, triglycerides, high density lipoprotein and a fall in low density lipoprotein. Treatment with HA extracts $(500 \mathrm{mg} / \mathrm{kg}$ ) daily for 17 days (Table 1$)$, significantly $(P<0.05)$ lowered the serum total cholesterol, LDL-C, triglycerides and HDL-C levels compared to those of both the treated and untreated controls.

Table 1: Mean blood glucose levels during a 17-day sub-chronic anti-diabetes study of the leaf extracts of $H$. acida in alloxan induced diabetic rats.

\begin{tabular}{|l|c|c|c|c|}
\hline $\begin{array}{c}\text { Test Extract } \\
\mathbf{5 0 0} \mathbf{~ m g / k g}\end{array}$ & $\mathbf{0 ~ H r s}$ & $\mathbf{3 ~ H r s}$ & $\mathbf{6 ~ H r s}$ & $\mathbf{1 2 ~ H r s ~}$ \\
\hline DAY 0 & $15.37 \pm 3.72$ & - & - & $26.65 \pm 3.86$ \\
\hline DAY 5 & $19.47 \pm 6.54^{\mathrm{b}}$ & $17.46 \pm 5.75$ & $15.70 \pm 5.42$ & $9.73 \pm 4.08$ \\
\hline DAY 11 & $11.79 \pm 5.06$ & $14.77 \pm 6.56^{\mathrm{a}}$ & $11.48 \pm 4.63$ & $8.76 \pm 4.03$ \\
\hline DAY 17 & $8.86 \pm 2.99$ & $9.28 \pm 2.70$ & $10.47 \pm 5.98^{\mathrm{a}}$ & $8.52 \pm 4.02$ \\
\hline $\begin{array}{c}\text { Glibenclamide } \\
\mathbf{2} \mathbf{~ m g / k g}\end{array}$ & & & & \\
\hline DAY 0 & $21.06 \pm 6.17$ & - & - & $25.26 \pm 6.32$ \\
\hline DAY 5 & $24.09 \pm 8.69$ & $20.14 \pm 5.16$ & $22.34 \pm 3.67$ & $17.66 \pm 3.44$ \\
\hline DAY 11 & $19.31 \pm 6.47$ & $19.50 \pm 6.10$ & $17.60 \pm 5.46$ & $15.01 \pm 5.66$ \\
\hline DAY 17 & $16.06 \pm 8.65$ & $13.86 \pm 7.70$ & $15.29 \pm 11.22$ & $9.99 \pm 8.38$ \\
\hline Distilled Water & & & & \\
\hline DAY 0 & $18.21 \pm 6.53$ & - & - & $22.63 \pm 5.63$ \\
\hline DAY 5 & $29.73 \pm 5.04$ & $26.24 \pm 5.66$ & $27.14 \pm 7.12$ & $26.59 \pm 4.49$ \\
\hline DAY 11 & $17.36 \pm 4.18$ & $19.51 \pm 6.10$ & $20.50 \pm 6.23$ & $25.86 \pm 4.79$ \\
\hline DAY 17 & $21.94 \pm 6.58$ & $23.55 \pm 5.42$ & $25.41 \pm 6.58$ & $25.70 \pm 5.66$ \\
\hline
\end{tabular}

$a$ values are significantly different from positive control, glibenclamide $(P<0.01)$.

$b$ values are significantly different from negative control, distilled water $(P<0.05)$.

Values are postprandial blood glucose levels in each group expressed as mean \pm S.E.M.

\section{Discussion}

The methanol extract of the leaves of $H$. acida gave a yield of 5.5\% w/w dry matter and did not produce death at doses used in the study. No death was recorded even at a high dose of $2000 \mathrm{mg} / \mathrm{kg}$, which is an indication that the extract was well 
tolerated by the rats. However, the rats showed signs of dullness which indicates that the extract may have depressive effects on the central nervous system.

Experimental rats were considered diabetic when the blood glucose levels of alloxan induced diabetic rats were 16.4 $\mathrm{mmol} / \mathrm{dl}$ and above (Vinuthan et al., 2007). The extract of $H$. acida did not indicate a dose-dependent effect being that the response with the highest dose of $1000 \mathrm{mg} / \mathrm{kg}$ did not produce better hypoglycaemic activity as expected. This is suspected to be as a result of the saturation of receptors. The extract however showed a consistent time-dependent decrease in the fasting blood glucose levels of test rats at a dose of $500 \mathrm{mg} / \mathrm{kg}$ over a six-hr study period as against the $250 \mathrm{mg} / \mathrm{kg}$ and $1000 \mathrm{mg} / \mathrm{kg}$ doses; and was therefore the preferred dose for a prolonged (sub-acute) study. Hypoglycaemic effects of the $500 \mathrm{mg} / \mathrm{kg}$ dose of the extracts compared favourably with the positive control, glibenclamide, an oral sulfonylurea. The error bars were high in the least dose of $250 \mathrm{mg} / \mathrm{kg}$; this may be attributable to the varying individual responses noticed in the group. This is sometimes observed in in vivo biological experiments involving whole animals.

The results obtained with the methanolic extract of $H$. acida portray the extract as a potential effective anti-diabetic agent. However, in all the experiments carried out in this study, relatively higher doses of the extract were needed to achieve an effect comparable to that of glibenclamide. This could likely be due to the crude nature of the extract used for the experiments.

Following the treatment of rats with alloxan, a remarkable increase in the levels of serum total cholesterol and low density lipoproteins were observed. It has earlier been reported that, elevated TC and LDL-C levels in the blood of diabetics are considered to be a prime cause of coronary heart disease (CHD) (Gutstatin and Fuster, 1999; Genset et al., 1991; Rodrigues and McNeil, 1986). Many epidemiological studies showed that drug or diet induced reduction of TC and LDL-C could reduce the risk of CHD (Levine et al., 1995; Scott and Grundy, 1979; Kannel and McGee, 1979). In the present study, the extract of H. acida showed a marked decline in the TC and LDL-C levels in serum compared to the untreated control, coinciding with aforementioned observations. This therefore unearths the cardio-protective effect of $H$. acida.

The results of this study indicate that the methanolic leaf extract of $H$. acida possesses significant anti-diabetic properties following oral administration. HA leaf extracts evidently reduced serum lipid levels associated with diabetes mellitus. This confirms the validity of the local use of HA leaves for the treatment of diabetes mellitus. The methanolic extract of $H$. acida leaves reduces serum lipid profile, indicating a protective role against diabetes induced hyperlipidemia.

\section{Acknowledgement}

The authors wish to acknowledge the Step-B institutional research grant for the study of plants with anti-diabetic potentials given to the University of Nigeria, Nsukka.

\section{References}

1. Allain, C.C., Poon, L.S., Chan, C.S., Richmond, W. and Fu, P.C. (1974). Enzymatic determination of total serum cholesterol. Clin. Chem. 20: 470-475.

2. Bergmenyer, H.U. (Editor) (1985). Methods of enzymatic analysis. $3^{\text {rd }}$ Ed. Vol. 8: 154-160.

3. Dewanjee, S., Bose, S.K., Sahu, R. and Mandal, S.C. (2008). Anti-diabetic effect of matured fruits of Dispyros peregrina in alloxan-induced diabetic rats. Int. J. Green Pharm.2: 95-99.

4. Footsati, S. and Principe, L. (1982). Serum triglycerides determined colorimetrically with an enzyme that produces hydrogen peroxide. Clin. Chem. 28: 2077-2080.

5. Friedewald, V.T., Levy, R.I. and Fredrickson, D.S. (1972). Estimation of low density lipoprotein cholesterol in plasma, without use of preparative centrifuge. Clin. Chem. 18: 499-502.

6. Genset, J.J., MCnamara, J.R., Salem, D.N. and Sehaeffer, E.J. (1991). Prevalence of risk factors in men with premature coronary artery disease. Am. J. Cardiol. 67:1185-1189.

7. Gutstatin, D.E. and Fuster, V. (1999). Pathophysiology and clinical significance of atherosclerotic plaque rupture. Cardiovasc. Res. 41:323-333.

8. Igoli, J.O., Igwue, I.C. and Igoli, N.P. (2003). Traditional medicinal practices among the Igede people of Nigeria. J Herbs Spices Med Plants 10: 1-10.

9. Igoli, J.O., Ogaji, O.G., Tor-Anyiin, T.A. and Igoli, N.P. (2005). Traditional medicine practice amongst the Igede people of Nigeria. Part II. Afr. J. Trad. Comp. Alt. Med. 2:134-152.

10. Kameswararao, B., Kesavulu, M.M. and Apparao, C. (2003). Evaluation of antidiabetic effect of Momordica cymbalaria fruit in alloxan-diabetic rats. Fitoterapia. 74:7-13.

11. Kannel, W.B. and McGee, D.L. (1979). Diabetes and cardiovascular risk factors: the Framingham study. Circulation. 59: 813.

12. Levine, G.N., Keaney, J.F. and Vita, J.A. (1995). Cholesterol reduction in cardiovascular disease-clinical benefits and possible mechanisms. N. Eng. J. Med. 332:512-521.

13. Miller, L.C. and Tainter, M.L. (1937). Estimation of $\mathrm{ED}_{50}$ or $\mathrm{LD}_{50}$ values and their error using log-probit graph paper. Proc. Soc. Exp. Biol. Med. 57:261. 
14. Muanza, D.N., Euler, K.L., Williams, L. and Newman, D.J. (1995). Screening for anti-tumor and anti-HIV activities of nine medicinal plants from Zaire. Int. J Pharmacog. 33: 98-106.

15. Rodrigues, B. and McNeil, J.H. (1986). Cardiac function in spontaneously hypertensive diabetic rats. Am. J. Physiol.251: 571-579.

16. Scoppola, A., Montecchi, F.R., Mezinger, G. and Lala, A. (2001). Urinary mevalonate excretion rate in type 2 diabetes: role of metabolic control. Atherosclerosis. 156: 357-361.

17. Scott M and Grundy. (1979). Diabetes and cardiovascular disease. Circulation. 100: 1134-1146.

18. Taskinen, M.R. (1987). Diabetes. Metabol Rev. 3:551-570.

19. Tona, L., Kambu, K., Mesia, K., Cimanga, K., Aspers, S., deBruyne, T., Pieters, L., Totte, J. (1999). Biological screening of traditional preparations from some medicinal plants used as anti-diarrhoeal in Kinshasa, Congo. Phytomedicine 6: 59-66.

20. Verspohl, E.J. (2002). Recommended testing in diabetes research. Planta Medica 68: 581-590

21. Vinuthan, M.K., Kumara, G., Narayanaswamya, M. and Veenab, T. (2007). Lipid lowering effect of aqueous leaves extract of Murraya koenigii (curry leaf) on alloxan-induced male diabetic rats. Phcog Mag. 3: 112-115.

22. Vonthron-Sénécheau, C., Weniger, B., Ouattara, M., Tra, Bi. F., Kamenan, A., Lobstein, A. (2003). In-vitro antiplasmodial activity and cytotoxicity of ethnobotanically selected Ivorian plants. J. Ethnopharmacol. 87:221-225.

23. Ward, J.W. and Elsea, J.R. (1997). Animal case and use in drug fate and metabolism, methods and techniques. Marcel Deker. New York. Vol. 2: 372-390. 